\title{
Aspectos Geológicos e Hidrogeológicos del Parque Nacional El Palmar, Entre Ríos, Argentina
}

\author{
Silva Busso Adrián ${ }^{(1,2)}$ y Patricio Machado $(\dagger)^{(3)}$ \\ (1) Depto. de Cs. Geológicas, FCEN, UBA Pabellón 2, Ciudad Universitaria, Buenos Aires (1407), Argentina. \\ silvabusso@yahoo.com.ar \\ (2) Instituto Nacional del Agua - DSH. Ruta Empalme J. Newbery km 1.628, Ezeiza, Bs. As. (1824), Argentina. \\ pntsas@ina.gov.ar \\ (3) GIGAM, Facultad de Ingeniería, Universidad Tecnológica Nacional (Regional Concordia). \\ Salta 277, Concordia, Entre Ríos (3200), Argentina. \\ machadopatricio@ hotmail.com
}

\begin{abstract}
RESUMEN
El Parque Nacional El Palmar ubicado en la Cuenca del Arroyo El Palmar (Entre Ríos, Argentina) constituye una reserva natural de carácter relíctico. Como área protegida su importancia radica en la población de palmeras Yatay (Butia yatay). Estas últimas están arealmente restringidas a la zona del parque nacional y sus inmediaciones, siendo poco frecuente observarlas en otros sitios del litoral platense. El área posee afloramientos de unidades de edad Cretácico representadas por la Fm. Puerto Yeruá sobre las cuales se depositan los sedimentos clásticos de edad Plio-pleistoceno de la Fm. Salto Chico (no afloran) y de edad Holoceno de la Fm. Ubajay en contacto neto. En esta zona pueden identificarse dos tipos de acuíferos, uno fisurado contenido en la Fm. Puerto Yeruá y dos acuíferos clásticos contenidos en la Fm. Salto Chico y la Fm. Ubajay. El primero de muy poco espesor y baja permeabilidad y el segundo de permeabilidad comparable pero más potente. El modelo hidroestratigráfico propuesto permite entender las variaciones laterales y verticales de las unidades involucradas potencialmente acuíferas
\end{abstract}

Palabras Clave: Geología, Hidrogeología, Palmar, Argentina, Cuenca.

\section{Geology and Hydrogeology Aspects of El Palmar National Park, Entre Ríos, Argentina}

\begin{abstract}
The El Palmar National Park located in the El Palmar Basin (Entre Ríos, Argentina) is a natural reserve of a relictic nature. As a protected area, its importance lies in the population of Yatay palm trees (Butia yatay). This type of palm tree is restricted to the area of the national park and its surroundings and it is uncommon to observe them in other locations on the platense coast. In the area there are outcrops of units of Cretaceous age represented by the Puerto Yeruá formation on which were deposited the clastic sediments of the Salto Chico formation of Plio-Pleistocene age (no outcrops) and the Ubajay formation of Holocene age in net contact. We identified two types of aquifers in the area, one fissured aquifer contained in Puerto Yeruá and two clastic aquifers contained in the Salto Chico and Ubajay formations. The first is of very thin and low permeability and the second of comparable permeability but thicker. The proposed hydrostratigraphic model has allowed us to understand the lateral and vertical variations of the aquifer units involved.
\end{abstract}

Keywords: geology, hydrogeology, palm grove, Argentine, basin.

\section{Introducción, objetivo y ubicación}

Este trabajo resume un conjunto de estudios con el objeto de realizar una caracterización geológica e hidrogeológica en el Parque Nacional El Palmar ubicado en la Cuenca del Arroyo El Palmar (aproximadamente Lat. $31^{\circ} 50^{\prime} \mathrm{S}$ - Long $\left.58^{\circ} 17^{\prime} \mathrm{O}\right)$. Se accede a él fácilmente desde la Ruta 14, Km 200 en el 
Departamento de Colón, Provincia de Entre Ríos, Argentina (fig. 1).

La zona se encuentra en un área de transición entre el clima subtropical y templado sin estación seca. Las temperaturas medias son de $26^{\circ} \mathrm{C}$ en verano y $13^{\circ} \mathrm{C}$ en invierno, oscilando la temperatura media anual de $20-21^{\circ} \mathrm{C}$ Las precipitaciones se encuentran entre los 1000 y 1400 mm El Parque Nacional Los Palmares constituye una reserva natural de carácter relíctico, se ubica en la "ecorregión del espinal" (APN, 2000), en la cual se suman las especies típicas del pastizal pampeano y de la selva paranaense, pero su importancia como área protegida radica en la población de palmeras Yatay (Butia yatay). Estas últimas están arealmente restringidas a una zona muy específica de la ecorregión, coincidente con el parque nacional y sus inmediaciones, siendo poco frecuente observarlas en otros sitios del litoral platense. Esta especie (Butia yatay) ya se reconoce amenazada y en disminución desde los primeros estudios de D Orbigny (1842), sin embargo no fue hasta 1965 que se crea el parque nacional con intención de proteger el palmar que cubre una extensión aproximada de 8.500 ha. No existe acuerdo, o al menos un estudio conclusivo, que explique la supervivencia del palmar en su ubicación actual. Se ha aludido a cuestiones edafológicas, geológicas, hidrológicas e hidrometeorológicas entre otras, pero ninguna ha sido suficientemente conclusiva para explicarlo. Desde una perspectiva ecológica, Micou (2003), alerta sobre el uso de suelo en la periferia del parque y sobre todo la forestación principalmente Eucalyptus grandis y en menor medida Eucalyptus dunni, Pinus elliottii, Pinus taeda y Eucalyptus globulus como un factor ecológico competitivo que afecta la población de palmeras.

Más recientemente Caruso (2013) menciona el riesgo y vulnerabilidad de la población de palmeras en relación a dos causas; una regional vinculada con la transformación de la ecorregión a causa de la introducción de la agroganadería; y otra más local relacionada con el avance de especies exóticas invasivas que resultan en perjuicio de la reproducción de las palmeras yatay. Dicho autor también destaca el impacto que el turismo tiene sobre el parque, considerando como un factor más que amenaza la supervivencia de este espacio ecológico. Aunque el estudio en detalle de las características geológicas hidrogeológicas de la zona está en una etapa inicial (Convenio IGME-UTN) ya se dispone de suficientes datos locales para realizar una caracterización adecuada de la geología e hidrogeología del mismo, lo que constituye el objetivo de este trabajo. Aunque aún estamos lejos de definir las causas que determinan la supervivencia o el carácter relictico de la población de palmeras del parque, creemos que este primer aporte es valioso sobre todo considerando la escasez de estudios de este tipo en los parques nacionales argentinos.

\section{Metodología}

La recopilación bibliográfica ha mostrado pocos estudios geológicos e hidrogeológicos realizados especí-

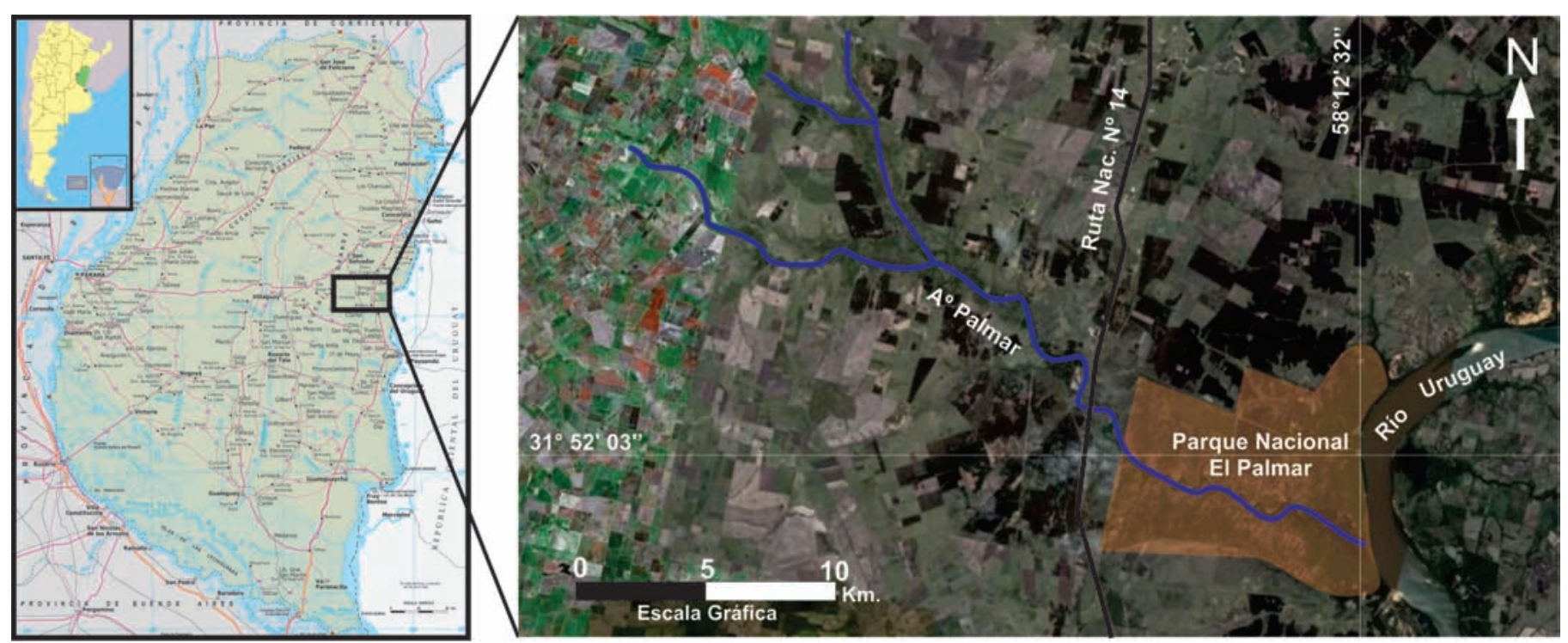

Figura 1. Ubicación regional y local del área de Parque Nacional El Palmar.

Figure 1. Geographic regional and local position of the El Palmar National Park. 
ficamente en el Parque Nacional El Palmar o que involucre algún dato tomado en el mismo. El primer estudio con una referencia directa a la geología local del parque es el de Gentile et al, (1974) donde fundamentalmente se describen los depósitos más recientes bajo la denominación de Fm Ubajay. Estos depósitos fueron nuevamente mencionados y un poco mejor definidos en Gentile y Rimoldi (1979). Los afloramientos locales de la Fm Puerto Yeruá fueron estudiados litológica y genéticamente pero, fueron interpretados en un contexto más regional (Tófalo, 1986). Si bien en lo sucesivo la geología e hidrogeología regional de la provincia ha sido objeto de algunos estudios (Bertolini, 1995; Silva Busso, 1999; Aceñolaza 2007; Santi et al, 2009; Silva Busso y Amato, 2017) la zona del parque nacional no ha sido específicamente mencionada o estudiada. Atendiendo esta falencia, hemos realizado diferentes campañas geológicas sucesivas desde el 2008 hasta la fecha que nos han permitido mejorar el conocimiento geológico e hidrogeológico de la zona del parque nacional e incluso de la cuenca del Arroyo El Palmar, donde se encuentra el parque. Esto ha incluido sondeos eléctricos verticales, perforaciones de estudio (que dieron lugar a la explotación local de agua subterránea para el control de incendios), estudios litológicos de recortes de perforación, estudios litológicos en afloramientos, ensayos de bombeo en captaciones de agua subterránea y campañas de muestreo hidroquímico. Resultados parciales o preliminares se han publicado en los últimos años (Masú et al, 2011; Silva Busso y Amato, 2013) pero no involucraron una visión integrada de la geología e hidrogeología del área del parque nacional. Los datos citados con la suma de otros, aún inéditos, condujeron a las interpretaciones presentadas en este estudio. También fueron la base de una segunda etapa más detallada que permitió instrumentalizar la zona de estudio con la medición y registro de datos hidrometeorológicos e hidrogeológicos. Esta última etapa se encuentra actualmente en ejecución, pero algunos datos hidrológicos y morfométricos relacionados con la cuenca del Arroyo El Palmar han sido incluidos para mejorar la caracterización propuesta.

\section{Antecedentes geológicos e hidrogeológicos}

El Parque Nacional El Palmar se encuentra en la provincia de Entre Ríos, cuya superficie se encuentra totalmente dentro de la cuenca Chacoparanense Argentina. La geología comienza con el Basamento Cristalino, alcanzado en profundidad por las perforaciones profundas (Silva Busso, 1999) y descrito como rocas graníticas, granitoides y tonalitas. Suprayacen a estos algunos niveles del Grupo Batoví, como la Formación Botucatú y Piramboiá. Litológicamente en estos niveles predomina la fracción clástica Limoarcilla (Fm. Piramboiá) por sobre la arena fina-media característica de los niveles eólicos de la Formación Botucatú (Silva Busso, 1999) de edadTriásico superior - Jurásico medio. La Formación Serra Geral, (Hausen, 1919; Gentile y Rimoldi 1979), es la de mayor extensión en la cuenca, tiene su génesis durante el periodo comprendido entre el Jurásico superior y el Cretácico inferior en función de la radimetría de las rocas basálticas que posee, (Tófalo ,1986 y Silva Busso, 1999). Ninguna de estas aflora en el área de estudio. La Formación Puerto Yeruá (De Alba y Serra, 1959) de edad Cretácico se describe como areniscas, brechas con silcretes y calcretes que afloran en el área del Parque y de hecho tienen allí su estrato tipo. De acuerdo conTófalo, (1986) se trata de variaciones laterales del mismo ambiente deposicional y proceso sedimentario fluvial proveniente del Este. La Formación Fray Bentos o Arroyo Avalos de edad Eoceno-Mioceno (Tófalo, 1986) constituyen un conjunto de rocas que afloran en diversas localidades sobre la costa del Río Uruguay desde Concepción del Uruguay hacia el norte de Entre Ríos, pero no lo hace en la zona del parque. Se compone de limos arenosos, con granos de cuarzo envueltos en una matriz arcillosa, con intercalaciones de loess y niveles de ceniza volcánica. La Formación Paraná, de edad Miocena y comúnmente representada en el subsuelo de la región como arcillas verde azuladas con intercalaciones de arenisca blanquecinas y cuarzosas, se encuentra ausente del registro geológico (Silva Busso y Amato, 2017). La Formación Salto Chico (Gentile y Rimoldi, 1979) se define como una sucesión de arenas cuarzosas, estratificadas de granulometría media a gruesa de color ocre rojizo y amarillento. Fueron interpretados como depósitos fluviales del río Uruguay pero de edad Plio-pleistoceno, la misma cruzaría el Río Uruguay a la actual altura de Colón (Iriondo, 1996). En el tope de la secuencia se compone de psefitas gruesas, situadas en la ribera derecha del Río Uruguay, cercanías de Arroyo El Palmar, y NE de Entre Ríos denominado Formación Ubajay (Gentili y Rimoldi, 1979) de edad supuesta Pleistoceno superior - Holoceno. En Iriondo (1980) se menciona esta unidad bajo el nombre de Formación El Palmar e interpretada como de origen fluvial siendo la expresión de la terraza alta del río Uruguay. No obstante, en este trabajo se respetará la denominación Fm. Ubajay por ser previo al anterior (Gentile et al, 1974; Gentili y Rimoldi, 1979). De acuerdo con Silva Busso y Amato (2017) la Fm. Salto Chico y la Fm. Ubajay son de difícil discriminación dado las semejanzas litológi- 
cas. La Fm. Salto Chico no aflora en el parque, pero se la halló en el registro del subsuelo. La Fm. Ubajay si aflora allí y cubre en casi todo el parque constituyendo la unidad parental de los suelos locales. Es importante mencionar que lateralmente y hacia el oeste la Fm. Ubajay desaparece de registro y comienzan los afloramientos de la Formación Hernandarias (Reig, 1956) que en la cuenca del Arroyo El Palmar constituye un limo arcilloso de color gris plomizo a verdoso de hasta decenas de metros de espesor, con finas láminas de arena y donde se observan intercalaciones de niveles yesíferos. La fracción arcilla es muy plástica, cohesiva y de composición montmoriIlonítica Esta formación constituye la cubierta cuaternaria que se extiende sobre la mayor parte de la provincia. Su origen se atribuye a un ambiente lacustre y palustre en clima seco y su edad por correlación sería Pleistoceno (Iriondo, 1994). Es previa a la Fm. Ubajay y esta última posee un contacto erosivo con la Fm. Hernandarias. En la Subregión Hidrogeológica XI o Subregión SistemaTermal Mesopotámico (Santa Cruz y Silva Busso, 1999) los acuíferos de la secciones interbasaltica e infrabasaltica (Sistema Acuífero Termal), si bien se considera que están presentes en profundidad y que el agua termal constituiría un aspecto relevante de la zona del parque, estos no se explotan localmente por lo que no forman parte del análisis este estudio; sobre este último aspecto puede considerarse los trabajos de Silva Busso, (1999); Silva Busso y Fernández Garrasino, (2004) y Mársico (2013).

La sección Suprabasáltica es de mayor interés por su claro vínculo con la ecología del parque. En el área de estudio ambos son en su totalidad acuíferos clásticos, aunque el grado de silcretización y calcretización de la Fm. Puerto Yeruá (primer unidad acuífera del registro suparabasaltico) determina que la misma

\begin{tabular}{|l|l|l|}
\hline \multicolumn{1}{|c|}{ Estratigrafía } & Hidroestratigrafía & \multicolumn{1}{c|}{ Tipo } \\
\hline Formación Ubajay & Epiparaneana & $\begin{array}{l}\text { Acuitardo/ } \\
\text { Acuífero }\end{array}$ \\
\hline Formación Hernandarias & Epiparaneana & Acuícludo \\
\hline Formación Salto Chico & Epiparaneana & Acuífero \\
\hline Formación Fray Bentos & Hipoparaneana & Acuitardo \\
\hline Formación Puerto Yeruá & Hipoparaneana & $\begin{array}{l}\text { Acuífero } \\
\text { fisurado }\end{array}$ \\
\hline
\end{tabular}

Cuadro 1. Hidroestratigrafía Suprabasaltica de la zona del Parque Nacional El Palmar.

Table 1. The supra basaltic hydrostratigraphy of the El Plamar National Park zone. se comporte como un acuífero fisurado. En esta región el Epiparaneano estaría representado por el Acuífero Salto Chico que subyace a los depósitos de las Formaciones Hernandarias o Ubajay. En la zona del parque solo aflora la Fm. Ubajay, dado que la Fm. Hernandarias se encuentra más hacia el oeste y es un acuícludo de extensión regional. Esta última posee características hidráulicas que las asemejan a acuitardos o acuíferos de baja permeabilidad y su extensión regional supera el área de estudio hacia el oeste, norte y sur. El cuadro 1 resume la hidroestratigrafía del área de estudio.

\section{Resultados y discusión}

\section{Geología e Hidrogeología de la cuenca del Arroyo EI Palmar}

Las determinaciones morfométricas de la cuenca hidrográfica del Arroyo El Palmar fueron realizadas sobre la base de Modelos de Terreno del ALOS (del inglés Advanced Land Observing Satellite), lo que permite una solución muy importante para generar los MDT (Machado et al., 2017). La elevada resolución espacial se consigue al realizarse las mediciones sobre la cuenca hidrográfica sin considerar la vegetación natural. Las curvas hipsométricas, que representan el área drenada en relación con la altura de la superficie de la cuenca, también han sido asociadas con las edades de los ríos de las respectivas cuencas (Strahler, 1976), comparando la curva hipsométrica del Arroyo El Palmar con las curvas teóricas (ver figura 2) muestran un arroyo joven a maduro en la cuenca media y alta y joven en la cuenca baja en cotas de entre 30 y 40 m s.n.m.

Esta observación coincide con las alturas donde se observa la transición lateral de la Fm. Ubajay a Fm. Hernandarias, la primera más reciente y por lo tanto los procesos erosivos aún son recientes. Esta zona es la cuenca baja y es donde se localiza el Parque Nacional El Palmar por lo que deducimos que aún es posible esperar procesos de erosión fluvial de suelos en el área de reserva. Otro elemento de análisis es la frecuencia de altitudes presentada en la figura 3. En base a esta distribución se determinó una altitud media de la cuenca de la cuenca de 55,00 m s.n.m., una altitud más frecuente de $52,50 \mathrm{~m}$ s.n.m. y una altitud de frecuencia media (Em) de 63,28 m s.n.m.

Por otro lado, considerando que el cambio litológico y la curva hipsométrica cambian entre los $30-40$ m s.n.m. y usando este criterio para definir el área de cuenca baja (donde se encuentra el parque nacional) se calcula que la misma alcanza solo al $13,63 \%$ del 

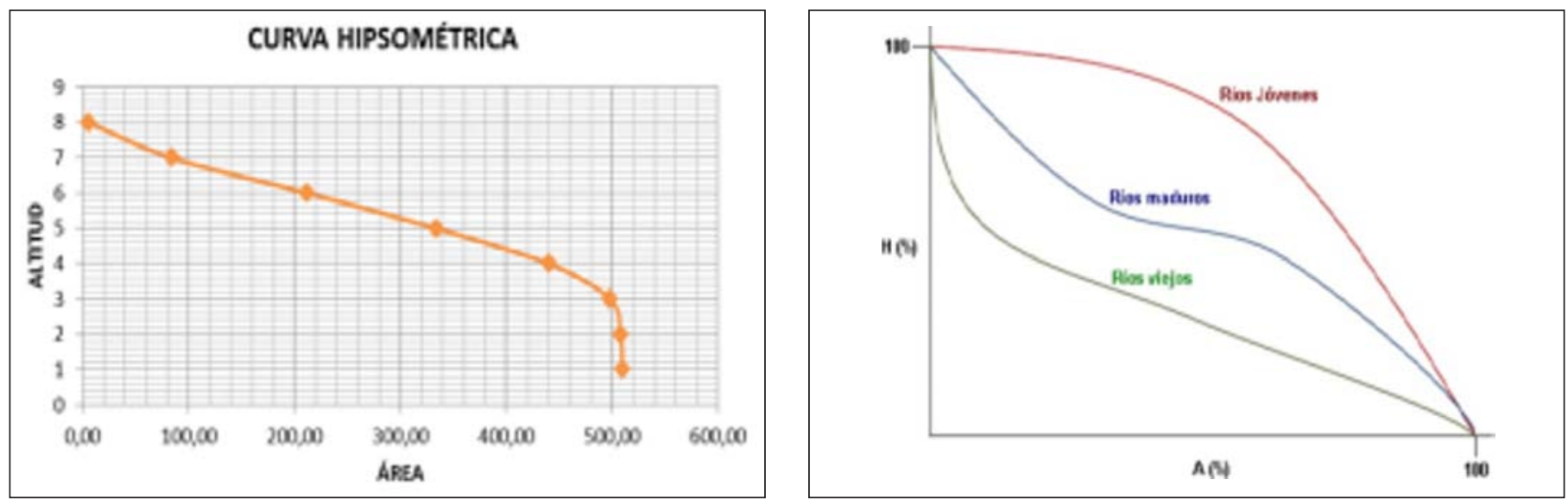

Figura 2. Curvas hipsométricas de la Cuenca del $A^{\circ}$ El Palmar (izq.) vs. Madurez de la cuenca en función de las curvas hipsométricas (derch.) según Strahler, (1976).

Figure 2. Hypsometric curves of the EI Palmar Cuenca del Arroyo(left) vs the maturity of the water basin based on the hypsometric curves (right) according to Strahler, (1976).

área total de cuenca. Iriondo \& Kröhling, (2008) proponen cambios dinámicos y geomorfológicos para el Río Uruguay del pleistoceno al reciente.

Esto sin duda tiene correlato en sus afluentes como el $\mathrm{A}^{\circ}$ El Palmar. Considerando que la cuenca media y alta resulta ser el $86,37 \%$ del área total y el cambio en la curva hipsométrica, interpretamos que este sector de la actual cuenca corresponde a otro perfil de equilibrio diferente al actual.

Es decir que con el nivel más elevado, hecho ocurrido hace unos 6000-8000 años aproximadamente (Silva Busso y Amato, 2009; Silva Busso y Amato,
2006), los depósitos actuales de la Fm. Ubajay eran la zona de cauce activo del Paleo Río Uruguay y esta porción de la cuenca ajustaba su perfil de equilibrio a esta circunstancia. Finalmente para el cálculo de la pendiente media de la cuenca se emplearon los datos del cuadro 2. Así se calculó una pendiente media de la cuenca: $16,62 \%$ (ondulado) y una pendiente media del cauce principal: $0,08 \%$.

Arealmente la cuenca del arroyo El Palmar presenta tres unidades aflorantes, la Fm. Puerto Yeruá sobre la costa del Río Uruguay, la Fm. Ubajay que cubre toda el área del parque nacional hasta la traza de la

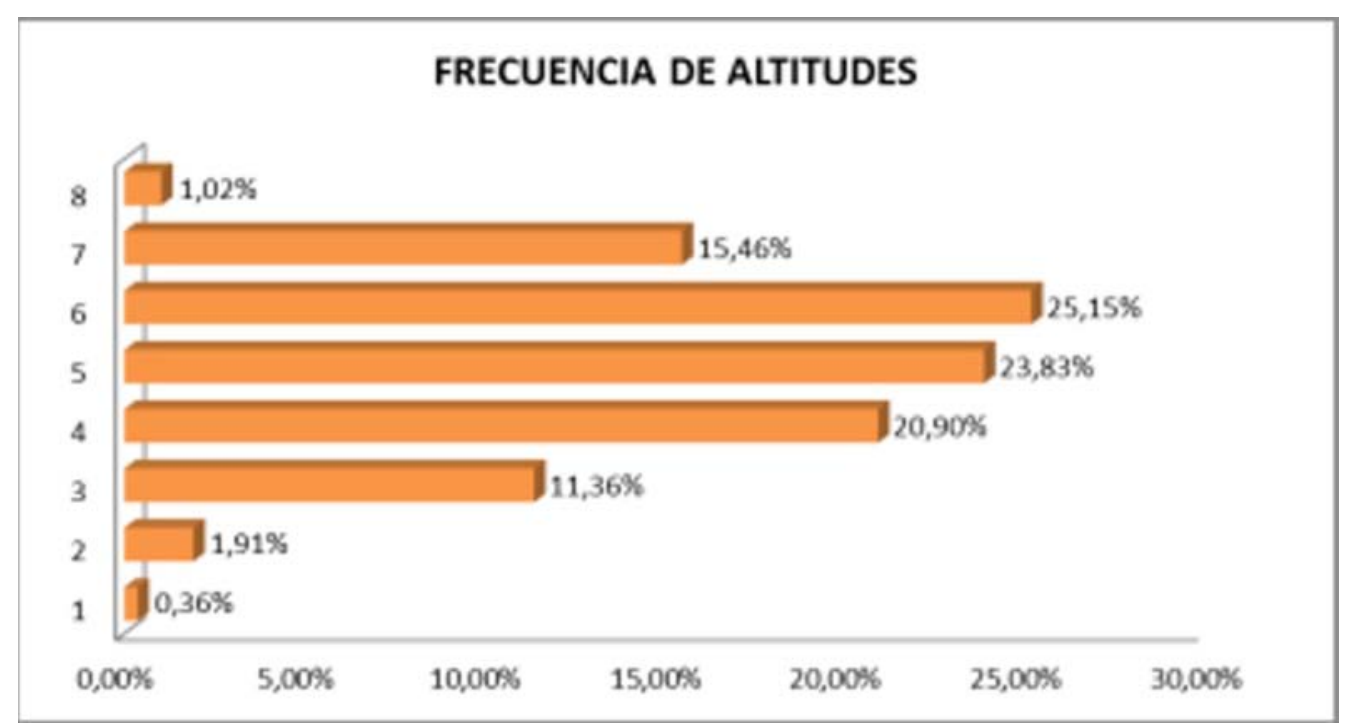

Figura 3. Distribución de la Cuenca del $A^{\circ}$ El Palmar.

Figure 3. Distribution of the El Palmar Cuenca del Arroyo. 
S. Busso Adrián y P. Machado, 2019. Aspectos Geológicos e Hidrogeológicos del Parque... Boletín Geológico y Minero, 130 (4): $773-788$

\begin{tabular}{|c|c|c|c|c|c|}
\hline \multirow{2}{*}{$\mathrm{N} 2$} & \multicolumn{2}{|c|}{ RANGO PENDIENTE } & \multirow{2}{*}{ PROMEDIO } & \multirow{2}{*}{$\begin{array}{l}\text { NÚMERO DE } \\
\text { OCURRENCIA }\end{array}$} & \multirow{2}{*}{$\begin{array}{l}\text { PROMEDIO } \mathrm{X} \\
\text { OCURAENCIA }\end{array}$} \\
\hline & INFERIOR & SUPERIOR & & & \\
\hline 1 & 0 & 5 & 2,5 & 3420 & 8550 \\
\hline 2 & 5 & 12 & 8,5 & 4887 & 41539,5 \\
\hline 3 & 12 & 18 & 15,0 & 5892 & 88380 \\
\hline 4 & 18 & 24 & 21,0 & 3693 & 77553 \\
\hline 5 & 24 & 32 & 28,0 & 2386 & 66808 \\
\hline 6 & 32 & 44 & 38,0 & 1064 & 40432 \\
\hline 7 & 44 & 100 & 72,0 & 568 & 40896 \\
\hline & & & & 21910 & 364158,5 \\
\hline
\end{tabular}

Tabla 1. Valores porcentuales usados para calcular la pendiente media de la Cuenca $\mathrm{A}^{\circ} \mathrm{EI}$ Palmar.

Table 1. Percentage values used to calculate the average slope of the El Palmar Cuenca del Arroyo.

ruta Nacional 14 aproximadamente y la Fm. Hernandarias aflorando en el sector medio y alto de la cuenca al oeste de la ruta nacional 14. Esto se ha detallado en el mapa de la figura 4 que incluye los pozos de estudio y los afloramientos revisados en este estudio.

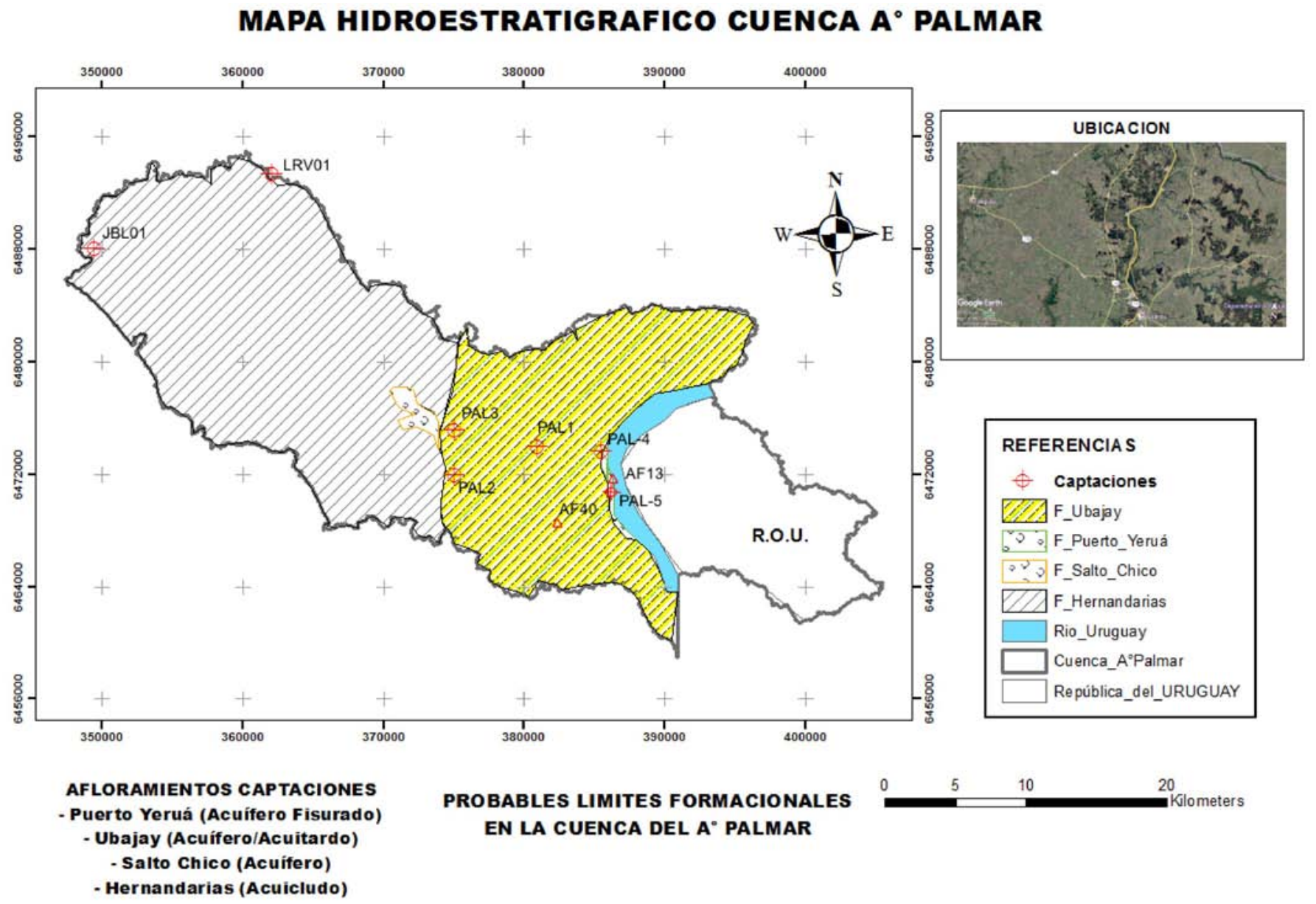

Figura 4. Geología, pozos de estudio y afloramientos de la Cuenca del $A^{\circ}$ El Palmar.

Figure 4. The geology, the studied wells and outcropping of the El Palmar Cuenca del Arroyo. 
Esto determina dos zonas diferentes desde la perspectiva hidrogeológica, una más oriental hacia la cuenca baja del arroyo El Palmar donde se encuentra el parque Nacional y otra más occidental que involucra las cuencas media y alta del mismo arroyo. La primera (oriental) en la cuenca baja de arroyo El Palmar aflora la Fm. Ubajay, aproximadamente entre la costa del río Uruguay (desembocadura) y la traza de la ruta nacional 14 (que por razones geotécnicas en general suele seguir el contacto entre Fm. Hernandarias y Ubajay). Como se describirá más adelante en esta región predominan sedimentos psamíticos de moderada a baja permeabilidad, la recarga vertical es el proceso dominante, los acuíferos tienden a ser libres o semilibres, las salinidades más bajas y una tendencia a comportarse como acuíferos multicapa. La segunda (occidental) en la cuenca media y alta de arroyo El Palmar aflora la Fm. Hernandarias aproximadamente entre la traza de la ruta nacional 14 y el límite de cuenca. Aquí se tata de sedimentos arcillosos de muy baja permeabilidad, la recarga vertical sería nula o escasa y ocurriría en los cauces cuando por erosión alcancen la Fm. Salto Chico (infrayacente y psefítico) en momento de elevada escorrentía a causa de las copiosas precipitaciones locales o los intensos episodios de tormenta. Esta Fm. Salto Chico contiene un acuífero de alcance regional, más potente, con mejores transmisividades, con tipo hidráulico semiconfinado o confinado, con salinidades son moderadas (mayores que en el caso anterior) y se trata de un acuífero claramente definido entre dos niveles acuitardos la ya mencionada Fm. Hernandarias y las arcillas infrayacentes de la Fm. Paraná. Las salinidades, a priori, son indicadores de condiciones de recarga diferentes consecuencia de la posibilidad de recarga vertical local y directa del Acuífero Ubajay. Masú et al., (2011) demuestra que las características geológicas de la zona, influyen y caracterizan a los acuíferos contenidos en los sedimentos fluviales de edad Plio-pleistoceno-actual y propone el corte de sección hidrogeológico de la figura 5 que atraviesa en sección Este-Oeste al acuífero. Este modelo hidroestratigráfico es la base conceptual (ver figura 4 y 5) de la cuenca hidrográfica del Arroyo El Palmar.

El área del Parque Nacional El Palmar se encuentra totalmente en la zona oriental ya mencionada, caracterizada en principio por las unidades geológicas visibles en margen oriental del corte hidrogeológico de la figura 5. En lo sucesivo se describirá y caracterizará la geología e hidrogeología hallable en el parque nacional que deber entenderse contextualizada en el marco regional propuesto para el área total de la cuenca hidrográfica que lo contiene.

\section{Caracterización geológica del parque nacional el pal- mar}

Se resume a continuación la columna estratigráfica aflorante en el área del parque y la descripción de las muestras geológicas de las captaciones de agua subterránea. La secuencia aflorante comienza con la Fm. Puerto Yerúa de edad Cretácico superior que aflora en la barranca del Río Uruguay. Sobre la misma unidad y con una ligera discordancia apoya la Formación Salto Chico de edad Plio-pleistoceno que no aflora en el parque pero es reconocida en las muestras de las perforaciones. Finalmente, la Formación Ubajay de edad Holoceno apoya sobre ambas con una ligera discordancia sobre la Fm. Puerto Yeruá y una discordancia erosiva sobre la Fm. Salto Chico y aflora en casi toda la superficie del parque.

\section{Corte Geológico de la Cuenca del Arroyo El Palmar, Entre Ríos}

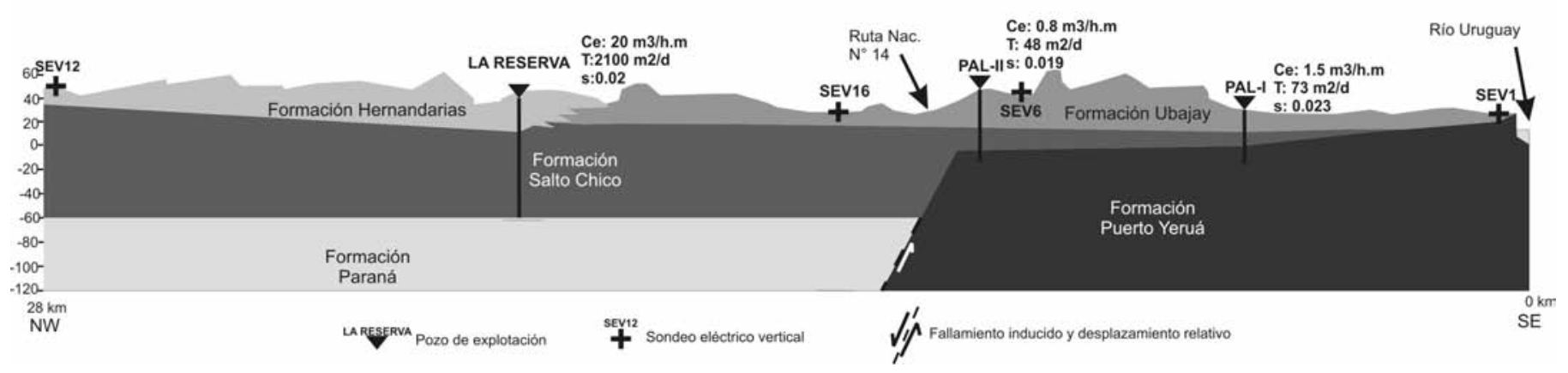

Figura 5. Modelo hidroestratigráfico de la Cuenca del Arroyo El Palmar. (Masú et al., 2011). Figure 5. Hydrostratigraphic model of the El Palmar Cuenca del Arroyo, (Masú et al., 2011). 


\section{Formación Puerto Yerúa (Cretácico sup)}

Esta es la unidad sedimentaria aflorante más antigua y correspondería al primer relleno de la subcuenca sobre la Fm. Serra Geral, que aflora en la vecina República Oriental del Uruguay. En dicho país según Bossi, (1966) y el mapa geológico de Bossi et al., (1975) se menciona un conjunto de sedimentos de edades Cretácico media a superior denominado Formación Guichón, Fm. Mercedes y Fm. Asencio de base a techo de la secuencia. Es este estudio se empleará la denominación de Formación Puerta Yeruá propuesta en Argentina primeramente por De Alba y Serra, (1959); aceptada en cierta medida por Gentili y Rimoldi, (1979) y finalmente estudiada con más detalle porTófalo, (1986) para denominar este conjunto de sedimentos y unidades en territorio argentino correlacionables con la Fm. Mercedes y la Fm. Guichón (dado que la Fm. Ascencio si es reconocible en terri- torio argentino $40 \mathrm{~km}$ al sur del parque nacional). Es oportuno mencionar que en Aceñolaza (2007) se la considera y describe como solo equivalente a $\mathrm{Fm}$. Guichón. La Fm. Puerto Yeruá se la ha descrito como un conjunto de areniscas finas a medianas de colores rojo y pardo rojizo con matriz pelítica rojo intenso. Probablemente la zona de mejor observación sea el área del Parque Nacional El Palmar, en el denominado perfil AF-13 en la barranca al pie del destacamento naval de la Prefectura dentro del parque (S:31 ${ }^{\circ} 54^{\prime} 09^{\prime \prime}$; O:-58 $12^{\prime} 13^{\prime \prime}$ a 4 m s.n.m.). Se presentan en afloramiento (fig. 6) como estrato subhorizontales y su espesor en la barranca posee unos $15 \mathrm{~m}$.

Desde la base, los primeros 5,5 metros corresponden a un conglomerado o brecha de color gris blanquecina en conjunto, pero con clastos pelíticos de color rojo o rosa pálido, masivos sin orden aparente, fuertemente consolidados con cemento silícieo. Se observa una intensa fracturación y/o diaclasamiento.

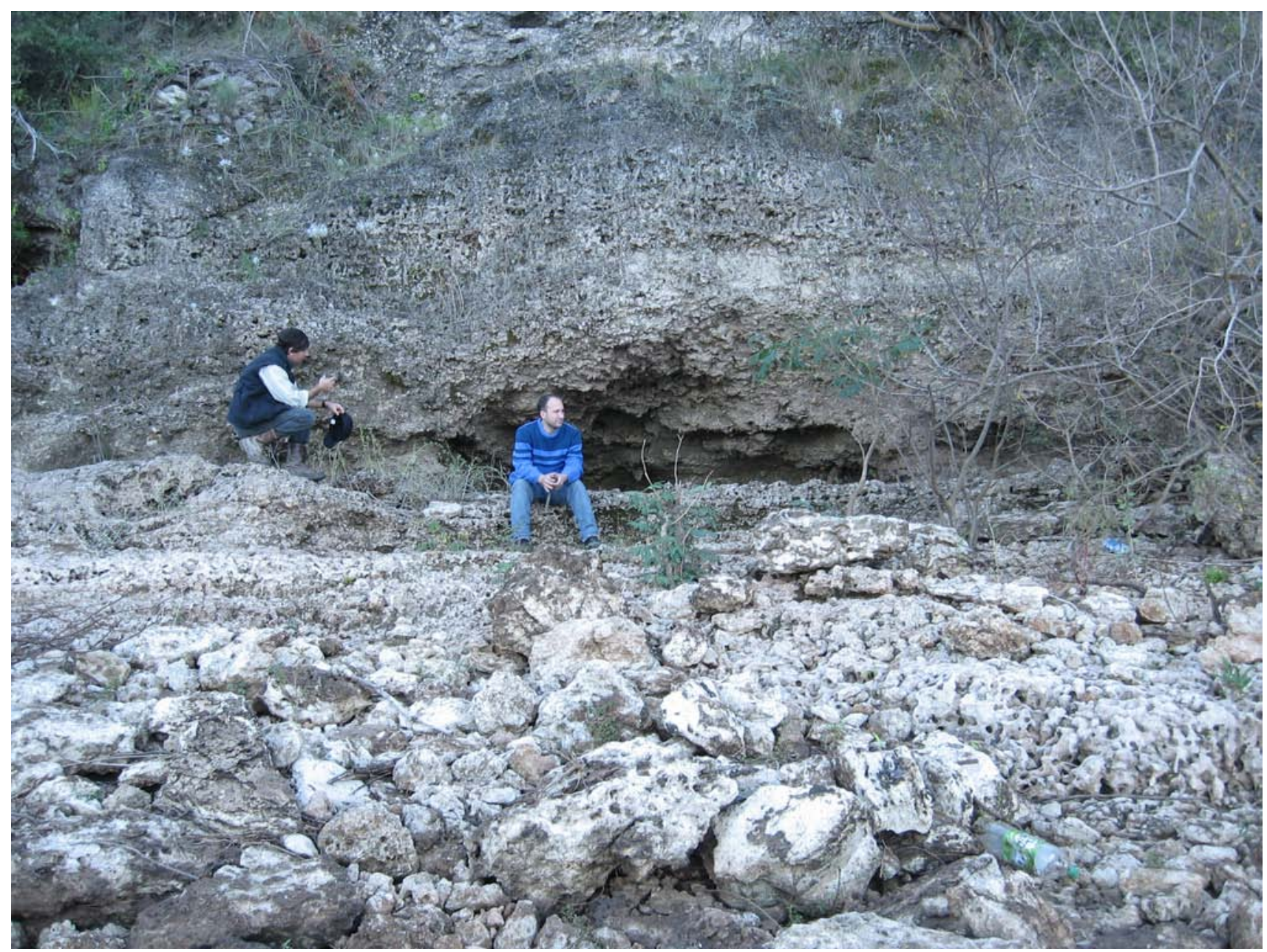

Figura 6. Formación Puerto Yeruá aflorante en Parque Nacional El Palmar.

Figure 6. The Puerto Yeruá formation outcropping in the El Palmar National Park. 
Hacia el techo, continúan 5 metros más de una arenisca de color gris blanquecino a rosado pálido, de tamaño de grano arena mediana que presenta intercalado material limo y/o arcillas de color rojo más intenso, granodecreciente, de composición cuarzosa, muy consolidada con cemento silíceo y carbonático en conjunto, incluso formando silcretes y calcretes interdigitados. Se observan lineaciones que podrían indicar estructuras de corriente (probable estratificación plana) pero la intensa fisuración del material impide una adecuada descripción. Por encima 4,5 metros se observa una arcilla limosa de color rojo intenso, masiva, consolidada (aunque menos que los niveles subyacentes) con cemento silíceo y carbonático en conjunto. Presenta una intensa fisuración. Finalmente en el techo se desarrolla el suelo actual.

Hacia el norte $(50 \mathrm{~km})$ en la Ciudad de Concordia Tchilingurián et al., (1998) observa la misma unidad y la describe considerándola el afloramiento más al norte en la zona costera del Río Uruguay. Silva Busso, (1999) cita lo que parece el afloramiento más al sur en la desembocadura del Arroyo de La Leche, en Colón $40 \mathrm{~km}$ más al sur y sugiere que probablemente, en momentos de estiaje, esta unidad puede constituir el fondo del Paso Paysandú ( 3 o 4 km aún más al sur del Arroyo de la Leche). Las muestras obtenidas de perforaciones del estudio PAL 1 (S: $31^{\circ} 51^{\prime} 52^{\prime \prime} ; 0$ : $58^{\circ} 15^{\prime} 30^{\prime \prime}$ a 28 m s.n.m.) y PAL 2 (S: 31 $52^{\prime} 56^{\prime \prime}$; O: $58^{\circ} 19^{\prime} 13^{\prime \prime}$ a 20,5 m s.n.m.) en el parque (ver figura 2 ), ambas de 40 metros de profundidad, corresponden a una arenisca blanquecían a rosada de textura sacaroide y fuertemente silcificada. La edad es Cretácico superior determinados sobre la base de los hallazgos de fragmentos óseos del dinosaurio Argyrosaurus superbus realizados por Von Huene (1929) en Calera Barquín, hoy incluida como patrimonio histórico dentro del Parque Nacional El Palmar. Esta unidad se presenta siempre muy alterada y diaclasada, con múltiples sistemas de fractura, lo que determina el interés hidrogeológico sobre la banda derecha del Río Uruguay.

\section{Formación Salto Chico (Plio-pleistoceno)}

Esta unidad no aflora en el área del Parque Nacional El Palmar pero ha sido reconocida sobre la base de las muestras litológicas de las captaciones PAL-1 y 2 ya mencionadas (existe una captación PAL $3 \mathrm{~S}$ : 31 $51^{\prime} 12^{\prime \prime}$; O: $58^{\circ} 19^{\prime} 11^{\prime \prime}$ a $35 \mathrm{~m}$ s.n.m. de la que no se posee información geológica ni hidrogeológica). Es una unidad sedimentaria de origen fluvial, fue observada y descrita en la Rep. Oriental del Uruguay por Lambert, (1940) en lo que hoy es su término correla- cionable la Fm. Salto, nombre asignado a esta unidad por Goso (1965). Observada más tardíamente en Argentina, Rimoldi (1963) le da la denominación actual y amplia referencias sobre esta en Gentili y Rimoldi, (1979). Los afloramientos descritos por dichos autores, han sido cubiertos por el llenado del Embalse de la Presa Salto Grande. En la actualidad son accesibles algunos afloramientos sobre la costa del Río Uruguay aguas debajo de la presa en momento de "embalsamiento de reserva". La litología de las perforaciones PAL 1 y 2 se describen como gravas clastososten con una matriz arcillo limosa de colores diversos pardo rojiza, blanquecía, castaño clara u otras (entre los 18 - $24 \mathrm{~m}$ de profundidad). Puede presentar intercalaciones de arcillas de color castaño claro y/o verdoso. Los clastos suelen ser de ópalo y calcedonia y en menor proporción de composición basáltica o arcillosa. Comúnmente de buena redondez y selección.

En los pozos más profundos ubicados hacia el oeste (zona de cabecera del Arroyo Palmar) esta unidad frecuentemente presenta dos ciclos fluviales bien represados. Los mismos están frecuentemente separados por un paquete arcilloso de poca potencia (Silva Busso y Amato, 2017). Como parte integral y correlacionable del sistema fluvial Plio-pleistoceno la verdadera extensión regional en profundidad supera ampliamente la zona de estudio aquí propuesta. Pero desde un punto de vista litológico esta facie sería correlacionable con la Fm. Salto la que como se mencionó aflora en la vecina República Oriental del Uruguay cerca y sobre la costa del Río Uruguay sobre todo al norte de Salto (Goso y Bossi, 1966; Bossi et al., 1975).

Hacia el este consideraremos su límite la transición con las arenas de la Fm. Ituzaingó. En el Parque Nacional El Palmar esta unidad subyace en contacto con la Fm. Ubajay siendo el tipo de contacto neto entre ambas y poseyendo litologías muy similares, de gravas y arenas intercaladas, que dificultan la identificación a ojos poco entrenados. Aunque algunas de las características de esta última son distintivas no están siempre presentes en el registro y con facilidad se confunden sus respectivos límites. Dado que no afloran en el parque se ha incluido una imagen del afloramiento más cercano (AF-09 Lat.: $31^{\circ} 21^{\prime} 54^{\prime \prime} \mathrm{O}$ Long: $57^{\circ} 59^{\prime} 46^{\prime \prime} \mathrm{S}$;) sobre el río Uruguay en la cercanías de la ciudad de Concordia (ver fig. 7).

\section{Formación Ubajay (Holoceno)}

La Formación Ubajay compuesta de psefitas gruesas, situadas en terrazas de la margen derecha del Río 


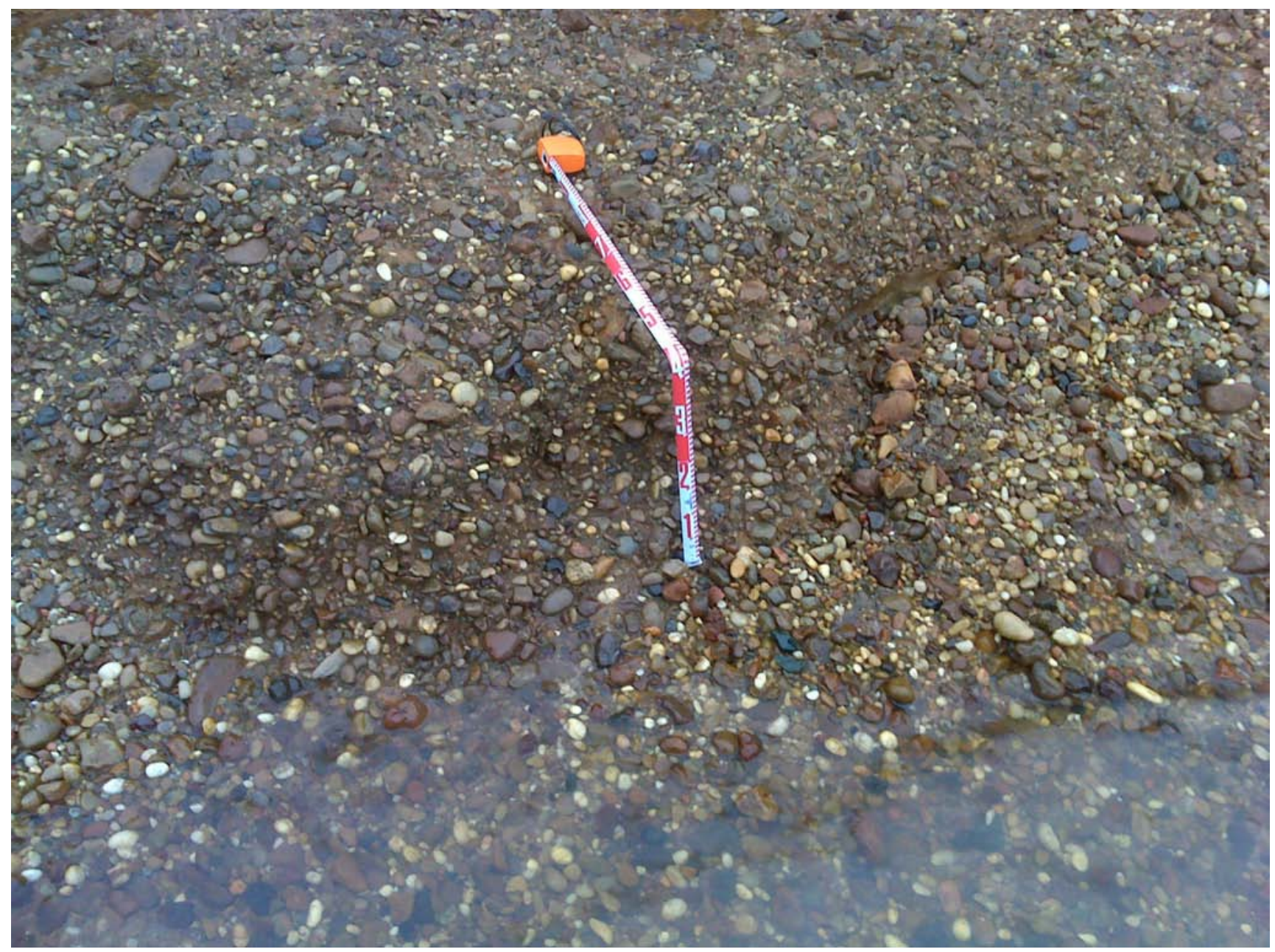

Figura 7. Detalle de la Formación Salto Chico (AF-09), Río Uruguay, Concordia.

Figure 7. Detail of the Salto Chico formation (AF-09), the Uruguay river, Concordia.

Uruguay fue definida por primera vez en el Arroyo EI Palmar, en la zona del parque y sus antiguas canteras (Gentili y Rimoldi, 1979). En el área de la costa Argentina del Río Uruguay se extiende ente la desembocadura del Río Mocoretá y la ciudad de Concepción de Uruguay, esta unidad representa hacia el oeste la expresión más reciente de estos depósitos fluviales, y las cotas altimétricas del techo coinciden en gran medida con la topografía del terreno. El techo toma valores desde $50 \mathrm{~m}$ s.n.m. en la divisoria de aguas de las Cuencas de arroyos afluentes del río Uruguay hasta aproximadamente los $10 \mathrm{~m}$ s.n.m. en la costa (Silva Busso y Amato, 2013 y Silva Busso Amato, 2017). Se le atribuye edad Pleistoceno superior - Holoceno y ha sido interpretada como la terraza alta del río Uruguay (Iriondo, 1996). En los afloramientos predominan las arenas finas a medianas de colores rojos, amarillentos y ocres donde intercalan niveles conglomerádicos matriz sostén de poco espesor con rodados de ópalo, calcedonia y cuarzo blanco y eventualmente fragmentos de basalto. También se observan intercalaciones de arcillas y limo de los colores ya mencionados. Hacia el techo se observa con frecuencia niveles silcretizados muy consolidados y de no más de un metro de espesor. Aunque Gentili y Rimoldi (1979) mencionan una matriz arenosa mediana a fina y un $10 \%$ de material limo arcilloso, Masú et al., (2011) observan porcentajes mayores, lo que además tiene una notoria influencia en su productividad acuífera. En las captaciones se encuentra representada en los primeros 18 metros de profundidad, de techo a base se describen como arenas medias a gruesas de color castaño a blanquecinas, intercalan limos de color amarillento, poco consolidados. Luego pasa a reconocerse un conjunto de arenas finas de color castaño amarillento que 
intercalan limos de igual color, presentando niveles poco consolidados. Finalmente se presentan arenas finas a muy finas de color castaño grisáceo que intercalan limos y arcillas de color gris claro. Existen diversos afloramientos en el parque nacional, aunque solo alcanza a verse la parte cúspide de la unidad. Las viejas canteras de áridos ya no presentan perfiles expuestos debido al crecimiento de la vegetación. Se ha incluido una imagen del afloramiento más representativa (AF-40 Lat.: $31^{\circ} 53^{\prime} 57^{\prime \prime}$ O Long: 58 $14^{\prime} 37^{\prime \prime}$ S;) sobre el Arroyo Palmar dentro del parque nacional (ver figura 8).

Finalmente, sobre la base de los afloramientos y las captaciones, se propone una columna litológica con el objeto de establecer las unidades geológicas atravesadas, definir un perfil integrado (figura 9) que permita reconocer mejor la hidroestratigrafía local y comprender el comportamiento de los acuíferos en la zona del parque (cuadro 2).

\begin{tabular}{|l|c|c|c|c|c|}
\hline Formaciones & $\begin{array}{c}\text { PAL-1 } \\
\text { mbbp }\end{array}$ & $\begin{array}{c}\text { PAL-1m } \\
\text { s.n.m. }\end{array}$ & $\begin{array}{c}\text { PAL-2 } \\
\text { mbbp }\end{array}$ & $\begin{array}{c}\text { PAL-2 } \mathbf{m} \\
\text { s.n.m. }\end{array}$ & Tipo \\
\hline Ubajay & $0-18$ & $28-10$ & $0-17$ & $20.5-3.5$ & Acuítardo \\
\hline Salto Chico & $18-24$ & $10 / 4$ & $17-33$ & $3.5 /-12.5$ & Acuífero \\
\hline Puerto Yeruá & $24-40 ?$ & $4 /-12 ?$ & $33-40 ?$ & $-16.5 / ?$ & $\begin{array}{l}\text { Acuífero } \\
\text { fisurado }\end{array}$ \\
\hline
\end{tabular}

Tabla 2. Interpretación estratigráfica local.

Table 2. Interpretation of the local stratigraphy.

Los valores de resistividad y gamma natural obtenidos mediante testificación geofísica, permiten interpretar y pueden corresponder a niveles de aporte de aguas dulces, arcillas o niveles calcretizados y/o silcretizados. La variación de la resistividad para una misma calidad de agua, obedece a diferencias litológicas en la formación. En general se han perfilado

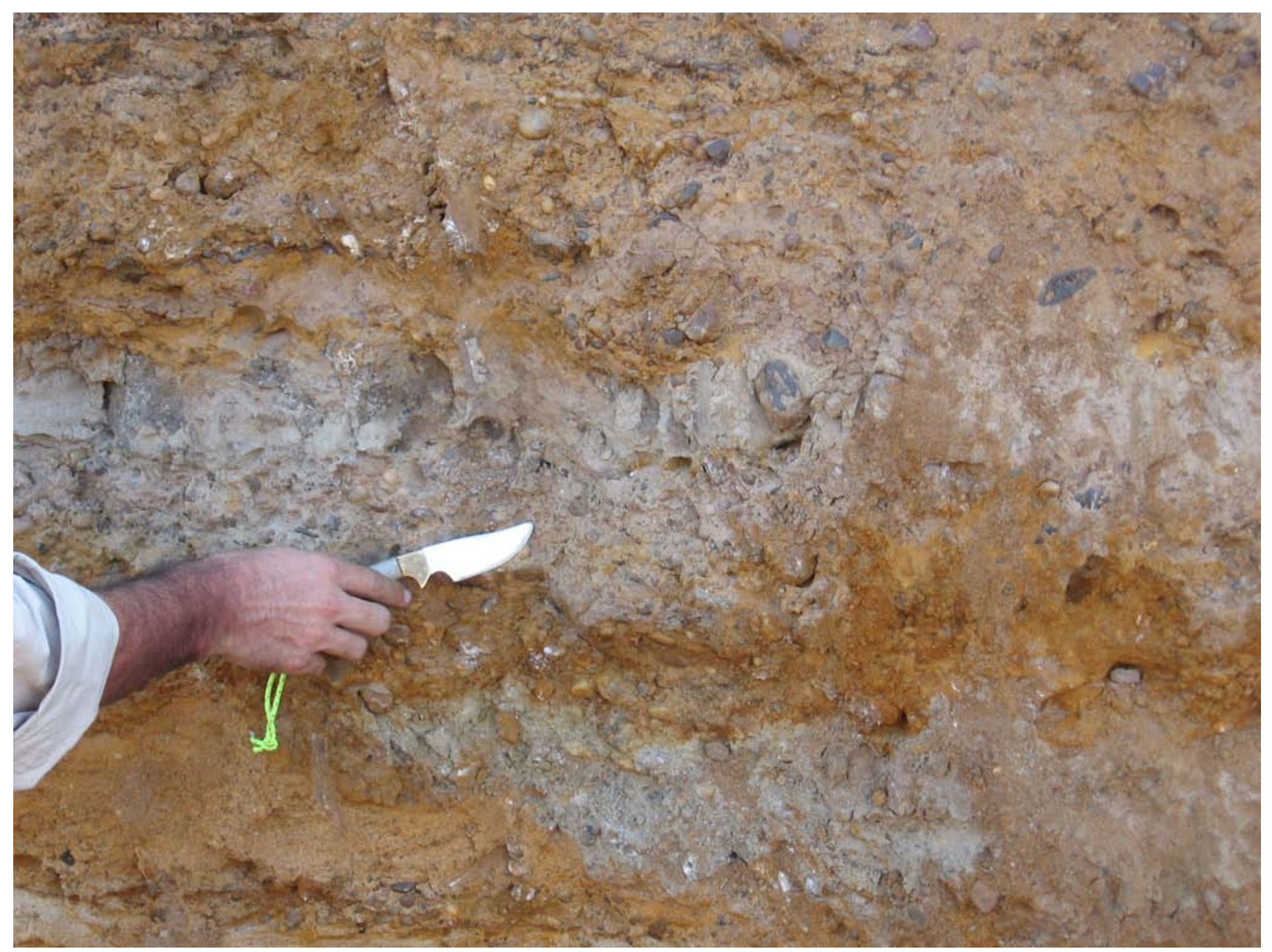

Figura 8. Detalle de la Formación Ubajay (AF-40) en el Parque Nacional El Palmar.

Figure 8. Detail of the Ubajay formation (AF-40) in the El Palmar National Park. 


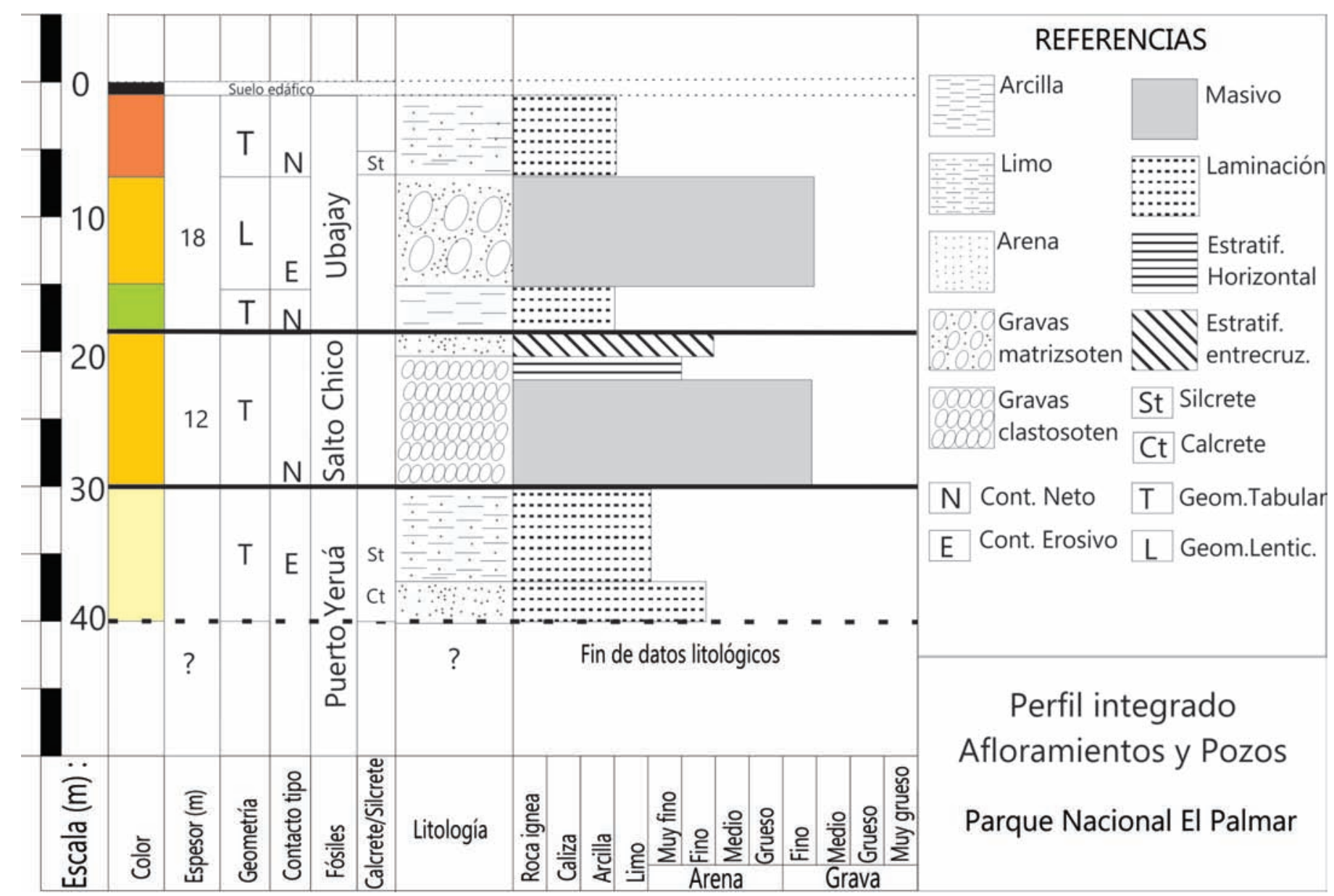

Figura 9. Perfil litológico integrado propuesto para la zona del Parque Nacional El Palmar.

Figure 9. Integrated lithological profile proposed for the El Palmar National Park.

entre 0 y $39 \mathrm{~m}$ de profundidad considerándose una aproximación satisfactoria para los Acuíferos Salto Chico y Puerto Yeruá. La Fm. Ubajay y Salto Chico acuñan hacia el este, (hacia la costa del Río Uruguay) donde aflora en la barranca la infrayacente $\mathrm{Fm}$. Puerto Yeruá.

\section{Caracterización hidrogeológica del parque nacional el palmar}

\section{Acuífero Ubajay}

A pesar de ser una unidad aflorante y a existir datos locales de las captaciones en la zona del parque nacional y alrededores debido su uso como acuífero, el Acuífero Ubajay es una unidad muy poco estudiada. Esto es en parte debido a su litología, fácilmente confundible con otras unidades fluviales más anti- guas aflorantes en la región (Fm. Salto Chico y Fm. Salto). Aunque recientemente se ha propuesto un estrato tipo definido para esta formación (Silva Busso y Amato, 2017) y un análisis de su arquitectura sedimentaria (Silva Busso y Amato, 2013), durante un largo tiempo la usencia de estos elementos de análisis dificultaron su identificación y diferenciación. Desde un punto de vista hidrogeológico los primeros estudios de esta unidad, son los que realiza Masú et al., (2011) en la cuenca del Arroyo El Palmar y Rossi (2012) en la Ciudad de Concordia (40km al norte), desde una perspectiva más relacionada con aspectos ambientales. Dada su litología podría suponerse, a priori, que se trata de un acuífero productivo. Sin embargo Masú et al., (2011) determinan que los contenidos mayores de un $10 \%$ de limo-arcilla tiene una notoria influencia en su productividad acuífera y discute esta observación con datos hidráulicos concretos, limitando su aprovechamiento hidrogeológico 
para su explotación, aún con poca demanda.También Rossi (2012) estudia la recarga local de esta unidad y algunos aspectos hidroquímicos. Menciona su uso en consumo humano pero también restringe su aprovechamiento descartando su explotación para riego. En el parque nacional se han ensayado las captaciones PAL-1 y PAL-2 con un ensayo de bombeo de 24 horas. Los caudales de bombeo fueron de $7,3 \mathrm{~m}^{3} / \mathrm{h}$ en PAL-1 y $11,5 \mathrm{~m}^{3} / \mathrm{h}$ en PAL-2 con un pozo de observación ubicado a 5 metros de las captaciones en ambos casos. La respuesta del acuífero puede interpretarse adecuadamente en el modelo hidráulico para acuíferos semilibres de Neuman, (1972) y puede observarse en la figura 10.

Sobre la base de los ensayos de régimen variable se obtienen los resultados de transmisividad $(T)$ y caudal específico (Ce) presentados en el cuadro 3.

Además, se han medido almacenamientos entre 0,01-0,02 (semilibre). Empíricamente en el terreno y con el auxilio de pozos cercanos se verifico un radio de influencia de $120 \mathrm{~m}$, para caudales de ensayo de $12 \mathrm{~m}^{3} / \mathrm{h}$ e ingresando en régimen permanente en aproximadamente 6 horas de bombeo. Se han medido respectivamente valores de salinidad total entre 100 a 300 mg/l en cada captación ensayada. La densidad de muestreo hidroquímico ha sido baja (solo una muestra por captación luego de 48 hs. de bombeo) permitiendo mostrar, como resultado los análisis de iones mayoritarios, aguas con salinidades bajas y de tipo bicarbonatadas sódicas. Este tipo de clasificación es típica en las áreas de recarga de toda la región pampeana.

\begin{tabular}{|l|c|c|c|c|c|}
\hline Captación & $\begin{array}{c}\text { Prof. Nivel } \\
\text { Estático } \\
\text { (m) }\end{array}$ & $\begin{array}{c}\text { Piezometría } \\
\text { (msnm.) }\end{array}$ & $\begin{array}{c}\text { Ce } \\
\mathbf{m} \mathbf{3} / \mathbf{h} . \mathbf{m}\end{array}$ & $\begin{array}{c}\mathbf{T} \\
\mathbf{m} 2 / \mathbf{d}\end{array}$ & $\begin{array}{c}\text { TDS } \\
\mathbf{m g} / \mathbf{l}\end{array}$ \\
\hline PAL-1 & 4,63 & 15,37 & 0,8 & 48 & 102 \\
\hline PAL-2 & 3,16 & 24,84 & 1,5 & 75 & 298 \\
\hline
\end{tabular}

Tabla 3. Datos hidráulicos calculados en los pozos PAL 1 y 2. Table 3. Hydraulic data calculated from the PAL 1 and 2 wells.

\section{Acuífero Salto Chico}

El Acuífero Salto Chico es intensamente explotado en la región, suele alcanzar un espesor de 70 a 80 metros Los caudales en sus pozos según Silva Busso (1999) oscilan entre 200 y $500 \mathrm{~m}^{3} / \mathrm{h}$ cada uno, aunque se han alanzado valores máximos de $800 \mathrm{~m}^{3} / \mathrm{h}$. Auge et al, (2005) han verificado caudales mayores a $100 \mathrm{~m}^{3} / \mathrm{h}$ al sudeste de Entre Ríos. Para los mencionados autores los parámetros hidráulicos medios son de una transmisividad 1.500 a $2.100 \mathrm{~m}^{2} / \mathrm{d}$, una permeabilidad de 30 a $72 \mathrm{~m} / \mathrm{d}$, y un almacenamiento entre $110^{-1}$ a $510^{-2}$ (Silva Busso, 1999). Santi et al., (2009) mencionan un porosidad efectiva del $20 \%$, y valores de almacenamiento de 1,2-3,2 $10^{-3}$ que le conferirían un comportamiento semiconfinado. La hidroquímica de esta unidad raramente muestra concentraciones salinas elevadas siendo aguas dulces en casi todas las localidades $\mathrm{y}$ en sus alumbramientos son fundamentalmente bicarbonatadas sódicas e incluso bicarbonata-
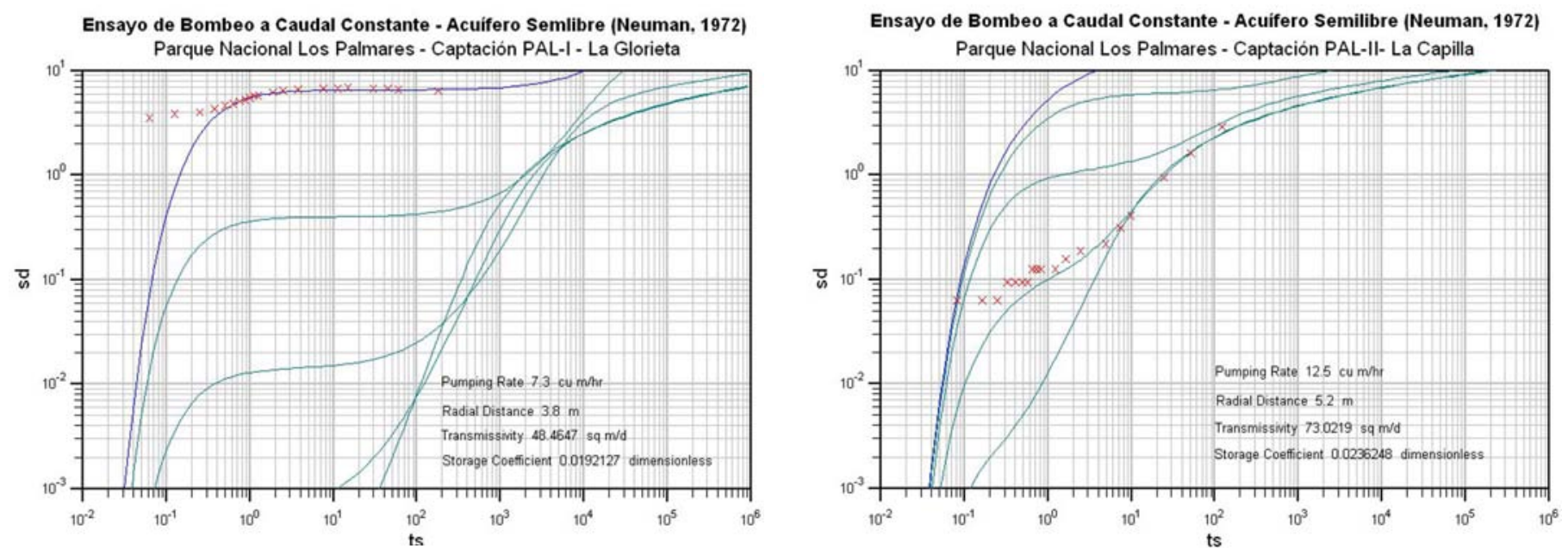

Figura 10. Interpretación por método de Neuman, (1972) para el Ac. Ubajay (izquierda PAL-1 y derecha PAL-2).

Figure 10. Interpretation by the Neuman method, (1972), for the Ubajay aquifer (PAL 1 on the left and PAL 2 on the right). 
S. Busso Adrián y P. Machado, 2019. Aspectos Geológicos e Hidrogeológicos del Parque... Boletín Geológico y Minero, 130 (4): $773-788$

das cálcicas. Santi et al., (2009) propone valores medios de $\mathrm{HCO}_{3}$ de $410 \mathrm{mg} / \mathrm{l}, \mathrm{Cl}(18 \mathrm{mg} / \mathrm{l}), \mathrm{SO} 4$ (15 $\mathrm{mg} / \mathrm{l})$ y $\mathrm{NO}_{3}(15 \mathrm{mg} / \mathrm{l})$. Entre los cationes el reparto es: $\mathrm{Na}(90 \mathrm{mg} / \mathrm{l}), \mathrm{Ca}(52 \mathrm{mg} / \mathrm{l}), \mathrm{Mg}(15 \mathrm{mg} / \mathrm{l})$ y $\mathrm{K}(3 \mathrm{mg} / \mathrm{l})$. En el parque nacional esta unidad posee un espesor de 6 metros, muy reducido con respecto a las captaciones situadas más al oeste producto del control estructural que se manifiesta sobre los depósitos fluviales Plio-pleistocenos (Silva Busso y Amato, 2017).

Su litología compuesta de arenas con elevado contenido de limos y arcillas que puede alcanzar el 10\% según Masú et al., (2011) determina que esta unidad no se explote localmente. Más al oeste Silva Busso et al., (2011) proporcionan datos procedentes de la localidad de Aldea Jubileo (JBL-1 S: $31^{\circ} 44^{\prime} 3.64^{\prime \prime}$; O: 58 35'19.57" cota: 69 m s.n.m.) con una potencia de 58 metros; y en cercanías de la ciudad de San Salvador en Estancia. La Reserva (LRV-1 S: 31 ${ }^{\circ} 41^{\prime} 16.11^{\prime \prime}$; O: 58 $27^{\prime} 16.13^{\prime \prime}$ cota: 64 m s.n.m.) con una potencia de 80 metros, Ambas dentro de la cuenca del Arroyo El Palmar. Se han ensayado ambas captaciones habiéndose obtenido respectivamente valores de tansmisividad de 3.100 y $1.700 \mathrm{~m}^{2} / \mathrm{d}$, un almacenamiento de $4,10^{-4}$ y de $1,10^{-3}$ de que reflejan un estado de funcionamiento confinado a semiconfinado con aguas cuya salinidad se encuentra entre 420 y $510 \mathrm{mg} / \mathrm{l}$. Si bien esta unidad no se explota localmente estaría conectada con el anterior acuífero Ubajay formando un sistema multicapa y de tipo hidráulico semilibre. Considerando estas unidades sin arcillas en la matriz (como suelen presentarse) y usando los espesores encontrados en el parque nacional (6 metros) sobre la base de las permeabilidades de mediadas en JBL-1 y LRV-1 las transmisividades estimadas (no se han ensayado captaciones en esta unidad en la zona del parque nacional) están entre 130 y $300 \mathrm{~m}^{2} / \mathrm{d}$.

\section{Acuífero Puerto Yeruá}

Casi no se conocen las características acuíferas del acuífero Puerto Yeruá (prácticamente no hay estudios hidrogeológicos sobre esta unidad). Su explotación se restringe a la zona de la banda occidental del río Uruguay donde es más somero, y donde constituye uno de los principales acuíferos empleados en abastecimiento humano, la producción avícola y la ganadería. A pesar de su génesis clástica la intensa calcretización y silcretización de esta unidad, aumenta su consolidación a punto tal de que es explotable en la mayoría de los casos como acuífero fisurado. No obstante, en las cercanías de la Ciudad de Colón se han realizado captaciones a los niveles psamíticos sin sil-

\begin{tabular}{|l|c|c|c|c|c|}
\hline Captación & $\begin{array}{c}\text { Prof. Nivel } \\
\text { Estático } \\
(\mathbf{m})\end{array}$ & $\begin{array}{c}\text { Piezometría } \\
(\mathbf{m s n m})\end{array}$ & $\begin{array}{c}\mathbf{C e} \\
\mathbf{m}^{3} / \mathbf{h} \cdot \mathbf{m}\end{array}$ & $\begin{array}{c}\mathbf{T} \\
\mathbf{m}^{2} / \mathbf{d}\end{array}$ & $\begin{array}{c}\text { TDS } \\
\mathbf{m g} / \mathbf{l}\end{array}$ \\
\hline PAL-4 & 22,1 & 5,9 & 0,68 & 20 & 317 \\
\hline PAL-5 & 14,3 & 5,7 & 0,58 & 16 & 412 \\
\hline
\end{tabular}

Tabla 4. Datos hidráulicos calculados en los pozos PAL 4 y 5. Table 4. Hydraulic data calculated from the PAL 4 and 5 wells.

cretizar respondiendo a un comportamiento de acuífero clástico.

En la zona del Parque Nacional existen dos captaciones del mismo (PAL-4 S: $31^{\circ} 52^{\prime} 06.4^{\prime \prime} ;$ O: $58^{\circ} 12^{\prime} 34.5^{\prime \prime}$

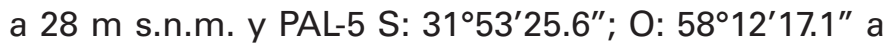
20 m s.n.m.) donde aflora y se explota como acuífero fisurado. Los datos calculados de caudal específico (Ce) y transmisividad (T, mediante ensayo de recuperación de Theis) se resumen en el cuadro 4 . No es posible comparar regionalmente estos datos dada la ausencia de un estudio hidrogeológico adecuado. No obstante, se han medido datos de transmisividad en la zona del Ejido de Colón explotado en condiciones de acuífero clástico que alcanzaron los $144 \mathrm{~m}^{2} / \mathrm{d}$ (inédito). Se trata de un acuífero de baja permeabilidad por fisuración, con niveles estáticos que están por debajo del nivel de agua de la superficie de del río Uruguay medido en 8,49 m s.n.m. Esto estaría indicando para el momento en que se evaluó el acuífero una posible recarga desde el río, aunque esta situación puede ser muy variable a lo largo del año dado que las oscilaciones del río a causa de las inundaciones periódicas y lluvias locales pueden estar entre 5 y 13 m s.n.m. (Machado y Zaramillo, 2005).

El análisis hidroquímico muestra aguas con salinidades bajas (TDS) del tipo bicarbonatada cálcica y/o sódica. Estas captaciones son localmente de las más importantes dado que abastecen de agua la intendencia del parque, el complejo habitacional, las zonas de acampada y el destacamento de Prefectura Nacional

\section{Conclusiones}

Las siguientes conclusiones se considerarán una caracterización hidrogeológica del área del área del Parque Nacional El Palmar. La cuenca del Arroyo EI Palmar posee una pendiente media de $16 \%$ y una pendiente media de cauce de $0.08 \%$. El área de cuenca alta y media cubre mayor superficie y posee un perfil que parece desequilibrado, mientras que la cuenca baja se encontraría ajustando el perfil de equilibrio al nivel de base actual. En el área se observan 
aflorando en la costa del Río Uruguay, unidades de edad Cretácico representadas por la Fm. PuertoYeruá. Sobre estas se depositan, en contacto neto, los sedimentos clásticos de la Fm. Ubajay de edad Holoceno. A excepción de la costa del Río Uruguay en toda la zona del parque aflora la Fm. Ubajay, más claramente visible en las barrancas del Arroyo Palmar. En perforaciones realizadas en el parque se pudo obtener información del subsuelo más hacia el oeste donde se verifica la presencia de la Fm. Salto Chico en el registro geológico, sobreimpuesta a la Fm. Puerto Yeruá e infrayacente a la Fm. Ubajay. La Fm Salto Chico acuña lateralmente hacia el Este hasta desaparecer del registro del subsuelo local. En función de los cambios litológicos, estructuras, distribución de los acuíferos y las salinidades de las aguas subterráneas se concluye que la zona corresponde a un área de recarga vertical sobre el Acuífero Ubajay con tendencia a comportarse como acuífero multicapa, sobre todo cuando el Acuífero Salto Chico aparece en la secuencia del subsuelo. De esta forma se identifican dos acuíferos clásticos uno contenido en la Fm. Salto Chico y orto en la Fm. Ubajay. El primero (Ac. Salto Chico) de muy buena permeabilidad pero localmente de muy poco espesor lo que limita su transmisividad razón por la que no se explota en la zona del parque. El segundo (Ac. Ubajay) de menor permeabilidad pero más potente. En la zona del parque sobre el Acuífero Ubajay se han determinado transmisividades ente 48 y $102 \mathrm{~m}^{2} / \mathrm{d}$, un almacenamiento de entre 0,01 y 0,02 (semilibre) y sus aguas poseen salinidades entre 102 y $298 \mathrm{mg} / \mathrm{l}$ son del tipo bicarbonatadas sódicas. También puede identificarse un acuífero fisurado contenido en la Fm. Puerto Yeruá. En el así llamado Acuífero Puerto Yeruá se han determinado transmisividades ente 16 y $20 \mathrm{~m}^{2} / \mathrm{d}$ siendo probablemente libre o semilibre dado que aflora en la zona de explotación. La salinidad de sus aguas varía entre 317 y $412 \mathrm{mg} / \mathrm{l}$ y son del tipo bicarbonatadas cálcicas/sódicas. Finalmente, el modelo hidroestratigráfico propuesto, válido para la zona del parque y toda la cuenca del arroyo El Palmar, permite entender las variaciones laterales y verticales de las unidades involucradas potencialmente acuíferas. Un aspecto importante y no menor es que varias de estas características (geológicas e hidrogeológicas) pueden extrapolarse a todas las cuencas interiores de vertiente hacia el Río Uruguay en la provincia de Entre Ríos.

\section{Referencias}

Aceñolaza, Fm. G., 2007. Geología y Recursos Geológicos de la Mesopotamia Argentina, INSUGEO Serie de Correlación Geológica 22, Tucumán, Argentina. 150 pp
APN, (2000). Las Eco-Regiones de la República Argentina. Secretaria de Ambiente y Desarrollo Sustentable, Buenos Aires. 43pp

Auge, M; Sánchez, C; Santi, M., 2005. Hidrogeología de la región arrocera de Entre Ríos. IV Congreso Hidrogeológico Argentino. Río Cuarto, Córdoba, Argentina.

Bossi, G., Ferrando L, Fernández A., Ellizalde G., Morales H., Ledesma J., Carballo, E., Medina E., Ford I.Y Montana J., 1975. Carta Geológica del Uruguay. Dirección de Suelos y Fertilizantes MAP, Montevideo, Uruguay. 1pp

Bossi, J., 1966. Geología del Uruguay. Universidad de la República, Departamento de Publicaciones, Colección Ciencias 2: 1-470, Montevideo, Uruguay

Caruso S.A., 2013. Análisis del riesgo ambiental de un área de valor de conservación: El Parque Nacional El Palmar. Vínculos asociados a la actividad turística en la provincia de Entre Ríos. Tesis de Licenciatura, Dpto de Geografía, Facultad de Filosofía y Letras, UBA. Inédito. 245pp

D'Orbigny, A., 1842. Voyage dans I'Amerique Meridionale. Pitoislevrautet et cie, Paleontologie Volume 3. Paris, France.

De Alba, E. y N. Serra, 1959. Aprovechamiento del Río Uruguay en la zona de Salto Grande. Informe sobre las condiciones y características geológicas. Dirección Nacional de Geología y Minería Anales 11, Buenos Aires, Argentina.

Gentili, C., Rosenman, H. \& Lourenco, A. 1974. Características geológicas generales del territorio brasileño, en la faja adyacente al curso medio del río Uruguay. Revista Asociación Geológica Argentina, Bs. As., 29 (2): 223-230.

Gentili, C. y H. Rimoldi, 1979. Mesopotamia. Academia Nacional de Ciencias, Segundo Simposio Geología Regional Argentina, Córdoba, Argentina. 1: 185-223.

Goso, H. Y Bossi, J. 1966. Cenozoico. En: Geología del Uruguay. Departamento de Publicaciones, Universidad de la República, Montevideo, Uruguay. 259 - 301.

Goso, H., 1965. El Cenozoico en el Uruguay. Ministerio de Industria y Comercio, Instituto Geológico del Uruguay, Montevideo, Uruguay. 26pp.

Hausen, J., 1919. Contribución al estudio de la petrografía delTerritorio Nacional de Misiones. Dirección General de Minas, Geología e Hidrología, Buenos Aires, Argentina. Boletín N²1 Serie B (Geología): 1-39.

Iriondo, M.H., 1980 El Cuaternario de Entre Ríos. Revista Asociación Ciencias. Naturales del Litoral. Santo Tomé, Vol. 11, pp. 125-141

Iriondo, M. H. 1996. Estratigrafía del Cuaternario de la Cuenca del Río Uruguay. XIII Congreso Geológico Argentino y III Congreso de Exploración de Hidrocarburos, Buenos Aires, Argentina. IV: 15-25.

Iriondo, M. \& D. Kröhling. 2008. Cambios ambientales en la cuenca del Uruguay (desde dos millones de años hasta el Presente). Colección Ciencia y Técnica, Universidad Nacional del Litoral. Santa Fe. 360 pp.

Lambert, R., 1940. Memoria explicativa de un mapa geológico de reconocimiento del Departamento de Paysandú y de los alrededores de Salto. Instituto Geológico del Uruguay, Montevideo, Uruguay. Boletín 27b: 1-41. 
Machado P, Silva Busso A., Chury M. Salarí, A. Ojeda, C. 2017. Determinación de Parámetros Hidrogeomorfológicos de la Cuenca del Arroyo Palmar AplicandoTécnicas de Teledetección. VI Congreso Bianual PROIMCA y IV Congreso Bianual PRODECA, Bahía Blanca. Argentina. Actas en CD: $\mathrm{N}^{\circ} 23$.

Machado y Zaramillo, 2005. Relevamiento y defensa de márgenes de la zona de ruinas del Parque Nacional El Palmar. Universidad Tecnológica Nacional Regional Concordia. Informe final Inédito. 97pp.

Mársico, D. 2013 Aportes a la perspectiva geológica e hidrogeológica regional en el sector centro este de la Cuenca Chacoparaneana. Tesis doctoral, Universidad de La Coruña. Inédita, La Coruña, España. 209pp

Masú J., Silva Busso A. y Amato S., 2011. Aspectos Geológicos del Acuífero Salto Chico en la Cuenca del Arroyo El Palmar, Provincia de Entre Ríos, República Argentina. VII Congreso Argentino de Hidrogeología y V Seminario Hispano Latinoamericano Sobre Temas Actuales de la Hidrología Subterránea, Salta, Argentina. Actas en CD. 56 - 60

Micou M. P., 2003. Riesgo ambiental por invasiones biológicas en una zona con alto valor de conservación Tesis de Licenciatura, Dpto de Geografía, Facultad de Filosofía y Letras, UBA. Inédito. 157pp

Neuman, S.P., 1972, Theory of flow in unconfined aquifers considering delayed response of the watertable, Water Resources Research, vol. 8, pp 1031-1045.

Reig, O., 1956. Sobre la posición sistemática de "Zygolestes paranensis" Amegh. y de "Zygolestes entrerrianus" Amegh. Centro de Estudiantes del Doctorado en Ciencias Naturales de Buenos Aires. Revista Holmbergia, Buenos Aires, Argentina. 5 (12-13): 209-226.

Rimoldi, H., 1963. Aprovechamiento del Río Uruguay en la zona de Salto Grande. Estudio geológico-geotécnico para la presa de compensación proyectada en el Paso Hervidero (provincia Entre Ríos). 1as. Jornadas Geológicas Argentina, Buenos Aires, Argetnina. Anales 2: $287-310$

Rossi A., 2012. Aspectos de la Contaminación con Nitratos en el Agua Subterránea de la Ciudad de Concordia, Entre Ríos. Trabajo Final Especialista en Ingeniería Ambiental, Universidad Tecnológica Nacional FRCON, Inédito, Concordia, Entre Ríos, Argentina. 63pp.

Santa Cruz J. N. y A. Silva Busso, 1999. Escenario hidrogeológico General de los Principales Acuíferos de la Llanura Pampeana y Mesopotamia Septentrional Argentina. II Congreso Argentino de Hidrogeología y IV Seminario Hispano Argentino sobre Temas Actuales en Hidrología Subterránea., Santa Fe, Argentina. Actas, Tomo I, Pág. 461-471.

Santi, M., Bianchi G. Y Rezzónico G., 2009. Agua subterránea en el noreste de Entre Ríos. VI Congreso Argentino de Hidrogeología. Planificación y gestión de aguas subterráneas Santa Rosa, La Pampa, Argentina. Actas 63-73.
Silva Busso A. Machado P. y Cosentino J., 2011. Propuesta de control de las estructuras del subsuelo sobre la geología Terciario-Cuaternaria y su relación con la geomorfología fluvial en la Provincia de Entre Ríos, Argentina. Convenio UTN (Concordia) - YPF, Universidad Tecnológica Nacional FRCON. Informe final Inédito. $245 p p$.

Silva Busso A. y Amato S. 2013. Posibilidades de Explotación y Demanda Hídrica sobre el Acuífero Ubajay en el Sector Oriental de la Provincia de Entre Ríos. $24^{\circ}$ Congreso Nacional del Agua, San Juan, Argentina. Actas: 2-56.

Silva Busso A. Y Amato S. 2017. Depósitos fluviales del Pliopleistoceno-holoceno de la Provincia de Entre Ríos y sus Implicancias Hidrogeológicas. Revista de la Asociación Geológica Argentina. Vol. 74 (3): 338 - 356.

Silva Busso A. y Amato S. D., 2009.Variaciones Paleoambientales e Hidroquímica del Acuífero Puelches en Área del "Delta del Río Paraná" VI Congreso Hidrogeológico y V Simposio Iberoamericano sobre temas actuales en Hidrogeología, Santa Rosa, La Pampa, Argentina. Acta en CD: 26-30

Silva Busso, A. 1999. Contribución al Conocimiento Geológico e Hidrogeológico del Sistema Acuífero Termal de la Cuenca Chacoparanense Oriental Argentina. Tesis Doctoral Inédita Facultad de Cs. Exactas y Naturales, UBA, Buenos Aires, Argentina. 504pp

Silva Busso, A. y Amato, S. 2006. Relaciones Estratigráficas e Hidroquímicas de los Acuíferos Pampeano y Puelches en el Noreste de la Provincia de Buenos Aires. Revista del Museo de Ciencias Naturales de la Ciudad de Buenos Aires. N8 (1) pag 9-26.

Silva Busso, A. y C. Fernández Garrasino, 2004.Presencia de las Formaciones Piramboiá y Botucatú (triásico - jurásico) en el subsuelo oriental de la Provincia de Entre Ríos, Argentina. Revista de la Asociación Geológica Argentina N59 (1): 141-151.

Strahler A, N 1992. Geografía Física. Editorial Omega 629 pp Tchilinguerán, P; Prez, H; Tejedo, A; Crespo, Cavallaro, S y Dzendoletas, A. 1998. "Carta Geológica ambiental de la Ciudad de Concordia, Provincia de Entre Ríos, Argentina" Congreso Uruguayo de Geología. Sociedad Uruguaya de Geología, Facultad de Ciencias, Punta del Este, Uruguay. Actas en CD s/n.

Tófalo, O., 1986a. Caracterización sedimentológica y estratigrafía de las Formaciones Puerto Yeruá y Arroyo Avalos, provincias de Entre Ríos y Corrientes. Tesis doctoral inédita Facultad de Ciencias Exactas y Naturales de la UBA, Buenos Aires, Argentina. 221pp.

Villanueva Martínez, M., Iglesias López, A., 1984. Pozos y Acuíferos. Técnicas de Evaluación Mediante Ensayos de Bombeo. ITGE, Madrid, España. 426pp

Von Huene, Fm., 1929. Los saurisquios y ornitisquios del cretáceo argentino. Anales Museo de La Plata III, 194 pp.

Recibido: julio 2018

Revisado: septiembre 2018

Aceptado: febrero 2019

Publicado: diciembre 2019 